\title{
DEMOCRATIZAÇÃO, AUTONOMIA, PROTAGONISMO, GOVERNANÇA: TRÊS INICIATIVAS NA EDUCAÇÃO SUPERIOR DE INDÍGÉNAS NO BRASIL ${ }^{1}$
}

\author{
RITA GOMES DO NASCIMENTO2 \\ $U F R N / M E C$
}

\begin{abstract}
RESUMO: $O$ artigo apresenta três iniciativas de criação de espaços próprios ou específicos de educação superior para os povos indígenas no Brasil. Os debates sobre a criação do Instituto dos Conhecimentos Indígenas e Pesquisa do Rio Negro (ICIPRN), do câmpus indígena da Universidade Federal da Fronteira Sul (UFFS) e da Rede Brasileira de Educação Superior Intercultural Indígena, a ser organizada pelo Ministério da Educação (MEC), têm mobilizado diferentes agentes e agências em torno do que se pode chamar de colaboração intercultural e interinstituicional. Nos exemplos descritos, os termos autonomia, protagonismo e governança são acionados pelos povos indígenas e demais atores sociais envolvidos como categorias estruturantes de suas ações.
\end{abstract}

PALAVRAS-CHAVE: educação superior; povos indígenas; instituições próprias $e$ específicas; colaboração intercultural; colaboração interinstitucional.

ABSTRACT: The article presents three initiatives of creation of own spaces or specific to higher education for indigenous peoples in Brazil. The discussions on the establishment of the Institute of Indigenous Knowledge and Research of the Rio Negro (ICIPRN), the Indian campus of the Federal University of South Border (UFFS) and the Brazilian Network of Intercultural Higher Education Indigenous being organized by the Ministry of Education (MEC) have been mobilizing different agents and agencies around what can be called intercultural and interinstitutional collaboration. In the examples described, the terms autonomy, leadership and governance are triggered by indigenous peoples and other social actors involved as structural categories of their actions.

KEYWORDS: higher education; indigenous peoples; specific institutions; intercultural cooperation; inter-institutional cooperation.

\footnotetext{
${ }^{1}$ Este artigo traz os resultados da pesquisa realizada no âmbito do Programa de Estudos Pós-doutorais da Universidad Nacional de Tres de Febrero (UNTREF) sob a supervisão do professor doutor Daniel Mato.

${ }^{2}$ Indígena do povo Potyguara do Ceará. Graduada em Pedagogia pela Universidade Estadual do Ceará. Mestre e Doutora em educação pela Universidade Federal do Rio Grande do Norte. Diretora de Políticas de Educação do Campo, Indígena e para as Relações Étnico-Racial do Ministério da Educação. Possui experiência de ensino e pesquisa nas seguintes áreas: diversidade étnica e cultural; formação de professores e políticas educacionais. E-mail: potyguara13@yahoo.com.br..
} 
A educação superior de indígenas no Brasil constitui-se um fenômeno recente na história da educação brasileira, na política indigenista nacional e, sobretudo, na história de vida dos povos e das pessoas indígenas. Mas também tem, desde cedo, sido objeto de estudos e pesquisas, com alguns dos seus resultados publicados em materiais impressos e em sítios eletrônicos ${ }^{3}$. Além disso, a oferta de educação superior aos povos indígenas tem constituído certa agenda governamental de políticas afirmativas surgidas em resposta às demandas educacionais trazidas à cena pública pelo movimento indígena.

Algumas dessas ações, implementadas nos últimos dez anos por diferentes atores institucionais, foram mapeadas em trabalho anterior (NASCIMENTO, 2015) com a intenção de fornecer subsídios para as reflexões nessa seara. O mapeamento objetivou, ainda, chamar a atenção, de um lado, para as estratégias de "inclusão social e étnicoracial" e, de outro, para as buscas por "autonomia e protagonismo indígena". Teve, assim, o intuito de evidenciar tanto o lugar dos povos indígenas e suas sociodiversidades nas políticas educacionais brasileiras quanto o papel do Estado em suas respostas institucionais às demandas educacionais indígenas.

Neste campo das políticas educacionais dirigidas aos povos indígenas no país, como desdobramento do mapeamento supracitado, o presente texto pretende apresentar algumas iniciativas recentes de criação de instituições específicas voltadas para o atendimento das demandas dos povos indígenas na educação superior.

Tais instituições estão ligadas aos esforços do movimento indígena em construir um sistema próprio de educação escolar indígena, da educação básica à educação superior, compreendido e reivindicado como lócus para o exercício do protagonismo, da autonomia, da autodeterminação e da governança indígenas. Esta reivindicação faz parte também de um movimento de contestação ao

\footnotetext{
${ }^{3}$ Um importante exemplo é dado pelos trabalhos desenvolvidos no âmbito do Projeto Trilhas de Conhecimentos, realizado no período de 2004 a 2009 pelo Laboratório de Pesquisas em Etnicidade, Cultura e Desenvolvimento (LACED) do Museu Nacional da Universidade Federal do Rio de Janeiro. Para maiores informações e acesso às suas publicações, consultar o endereço www.trilhasdeconhecimentos.etc.br. Merece destaque também o site https://ensinosuperiorindigena.wordpress.com/, ligado ao Núcleo de História Indígena e do Indigenismo (NHII) e ao Centro de Estudos Ameríndios (CEstA), ambos da Universidade de São Paulo (USP).
} 
modelo tradicional de universidade, fundado na produção monocultural de conhecimentos universalistas, eurocêntricos e colonialistas. Neste modelo, como é sabido, não encontram lugar as sociodiversidades indígenas, com suas diferentes cosmovisões, conhecimentos, línguas, sistemas econômicos e pedagogias próprias.

Por isso, a entrada dos povos indígenas na educação superior tem provocado mudanças em algumas de suas instituições, como a criação de políticas de acesso e permanência, espaços físicos específicos e instâncias de participação, além de fomentar os debates atuais em torno da criação de universidades, câmpus e institutos indígenas. Estes debates são o objeto central deste texto, que apresentará três iniciativas recentes que mobilizaram diferentes agentes e agências no cenário nacional.

As descrições de tais iniciativas foram baseadas nos documentos citados abaixo, que, por sua vez, visaram sistematizar e dar publicidade aos processos de construção de cada uma delas.

$\checkmark$ O livro Apoio à criação de uma instituição de ensino superior indígena (CGE, 2014), que trata da criação do Instituto dos Conhecimentos Indígenas e Pesquisa do Rio Negro (ICIPRN);

$\checkmark$ O projeto de criação do câmpus indígena da Universidade Federal da Fronteira Sul (BRASIL, 2014a)

$\checkmark$ As memórias das reuniões do grupo de trabalho (GT) instituído pelo Ministério da Educação (MEC) para realizar estudos sobre a criação de instituição de educação superior intercultural indígena e a versão de julho de 2015 do documento de trabalho do GT.

O texto está organizado em duas partes. A primeira apresenta um panorama da educação superior de indígenas no Brasil no que se refere ao acesso a cursos de graduação. A segunda traz uma descrição de três iniciativas na educação superior de indígenas que buscam atender as demandas específicas dos povos indígenas, colocando em perspectiva possíveis formas de colaboração intercultural e interinstitucional.

De maneira geral, os exemplos trazidos demonstram como as políticas de democratização da educação superior no Brasil podem ser situadas no âmbito de um movimento por maior acesso e formas de 
apropriação desta etapa de educação pelos povos indígenas, que acionam os termos autonomia, protagonismo e governança como categorias promotoras do seu bem-viver.

\section{Educação superior e povos indígenas: cenário atual de acesso a cursos de graduação}

Em que pese o processo de reestruturação da educação superior com vistas a sua democratização, as políticas educacionais não têm conseguido atender a contento as demandas por formação superior do conjunto da população brasileira, sobremaneira no que se refere a sua diversidade étnica.

O Brasil ainda apresenta baixos índices de acesso à educação superior frente a outros países da América Latina. De modo geral, os números referentes à quantidade e à qualidade desta etapa da educação revelam os modos pelos quais ela vem se constituindo historicamente como um "sistema de elite" (TROW, 2005).

Apesar do quadro de exclusões e desigualdades que cercam a educação superior, não se pode deixar de reconhecer que, nos últimos anos, foram implementadas significativas ações com vistas a sua democratização, ainda que o processo de expansão do acesso à educação superior em curso no Brasil não tenha conseguido romper com a tendência privatista e a concessão de privilégios para as elites econômicas.

No tocante ao acesso dos povos indígenas à educação superior, os números têm crescido a cada ano, refletindo, dentre outras coisas, os efeitos do crescimento de suas taxas de escolarização e de uma maior mobilização política das organizações indígenas e indigenistas em torno destas demandas.

Convém informar que as reivindicações dos povos indígenas por formações acadêmicas e profissionais encontram-se articuladas às estratégias etnopolíticas do movimento indígena, visando, de maneira geral, a garantia da posse e da sustentabilidade dos seus territórios, conjugadas com o imperativo estabelecimento de uma relação menos assimétrica com o estado nacional. 
É importante dizer que essas demandas são gestadas no momento em que a autonomia indígena ou sua autodeterminação figuram como condição sine qua non para a reversão da condição tutelar, juridicamente imposta pelo estado brasileiro desde o período colonial até a República e fortemente marcada nos diplomas legais que antecederam a promulgação da Constituição Federal de 1988. Autonomia e autodeterminação, portanto, estão na gênese do movimento indígena, compreendido como "aquele que é o elemento a questionar mais fortemente as tradições de conhecimento de nosso arquivo colonial", pretendendo dar "curso à polifonia indígena em nosso país", "onde o porta-voz branco, tutor, seja oficial ou não, deve ser ultrapassado" (SOUZA LIMA, 2007, p. 6).

Tem sido o movimento indígena, desde o final da década de 1980, o protagonista nas lutas e conquistas na área de educação escolar indígena, apesar de ainda hoje não terem muitas de suas demandas atendidas. Entretanto, no campo educacional, podem ser contabilizados alguns avanços que podem ser lidos também como sinais da busca de superação da tutela, tendo em vista que a educação era, até bem pouco tempo atrás, palco de atuação privilegiada dos não indígenas, oriundos de missões religiosas, de ONGs e de órgãos do estado.

Assim, o movimento indígena, de maneira semelhante a outros movimentos sociais, almeja

contar entre sus filas com profesionales dedicados a la defensa de los derechos de individuos y comunidades afectados por situaciones de injusticia social, así como com profesionales y técnicos dedicados a prestar servicios de apoyo a esos mismos sujetos sociales en diversos tipos de campos e iniciativas. También suelen impulsar actividades educativas, de difusión de sus ideas y de formación de cuadros, entre otras (MATO, 2010, p. 103).

Neste sentido, a presença de indígenas na educação superior, seja por meio de suas participações em cursos e programas convencionais já existentes ou inovadores - aqueles criados a partir de demandas indígenas -, seja através dos processos de criação e implementação de espaços acadêmicos, colegiados de participação, dentre outros criados nas estruturas das Instituições de Educação Superior (IES), coloca em 
primeiro plano uma crescente necessidade de maior escolarização e formação profissional entre os povos indígenas como forma de melhor instrumentalizar a conquista e a defesa dos seus direitos de maneira autônoma.

Vale, ainda, ressaltar que o conjunto de demandas por educação superior apresentadas pelos povos indígenas está inscrito em um cenário político que aponta para a importância da educação na busca de superação das desigualdades sociais. Assim, na educação superior, as políticas públicas têm posto como foco a ampliação do acesso dos que estudaram na escola pública, dos que possuem baixa renda e, ainda, daqueles que historicamente foram excluídos por seu pertencimento étnico e racial, como negros e indígenas.

É neste contexto que, no campo da legislação educacional, se observa a institucionalização da promoção da educação superior aos indígenas, ampliando as referências legais anteriores, que se limitavam apenas à educação básica. Sendo assim, é acrescentado à Lei de Diretrizes e Bases da Educação Nacional (LDB), pela Lei 12.416/2011, o $\S 3^{\circ}$ do artigo 79 , Título VIII, do ato das suas Disposições Gerais, que estabelece:

No que se refere à educação superior, sem prejuízo de outras ações, o atendimento aos povos indígenas efetivar-se-á, nas universidades públicas e privadas, mediante a oferta de ensino e de assistência estudantil, assim como de estímulo à pesquisa e desenvolvimento de programas especiais (Lei no 12.416 de 2011, § 30, Art. 79, Título VIII).

Associados a esse acréscimo, os artigos 78 e 79 já faziam referência a programas de ensino e pesquisa para a promoção da educação escolar bilíngue e intercultural, desenvolvidos pelo Sistema de Ensino da União, em colaboração com agências federais de fomento à cultura e de assistência aos índios. Pode-se depreender disso que tais programas deverão também ser extensivos à educação superior, tendo em vista a "formação de pessoal especializado, destinado à educação escolar nas comunidades indígenas"; o desenvolvimento de "currículos e programas específicos, neles incluindo os conteúdos culturais correspondentes às respectivas comunidades", dentre outros. 
No âmbito do planejamento educacional do país das duas últimas décadas, a referência à educação superior aos povos indígenas esteve inicialmente circunscrita à promoção de cursos para a formação de professores, embora houvesse no Plano Nacional de Educação (PNE) de 2001 a 2011 um capítulo dedicado à educação escolar indígena.

Já o plano de educação em vigor (2014-2024), em face do quadro atual de demandas indígenas e das políticas implementadas na área nos últimos anos, faz menção aos povos indígenas em estratégias que podem ajudar na promoção do acesso, da permanência e da conclusão com qualidade socialmente referenciada destes povos na educação superior.

Dessa maneira, a aprovação deste PNE traz para o cenário das políticas educacionais importantes estratégias que visam aprofundar o processo de democratização da educação superior, incluindo grupos historicamente excluídos, a exemplo dos povos indígenas. Como pode ser lido no PNE, há o reconhecimento da necessidade de implementação de ações afirmativas para o acesso considerando-se as especificidades dos grupos, da implementação de assistência estudantil para a garantia da permanência e do apoio a trajetória acadêmica para uma conclusão exitosa.

Outro aspecto que vem se destacando no cenário das políticas educacionais mais recentemente é o fato de que os sistemas de coleta de dados começaram a considerar a variável indígena na produção de suas informações. Embora ainda haja carência de instrumentos que melhor qualifiquem a presença de estudantes indígenas, o Censo da Educação Superior, realizado pelo Instituto de Estudos e Pesquisas Educacionais Anísio Teixeira (INEP), no âmbito do MEC, oferece dados importantes para a construção, implementação e avaliação das políticas de promoção de educação superior de indígenas. De acordo com os dados do levantamento realizado em 2014, há 22.030 estudantes matriculados em IES que se autodeclararam indígenas, distribuídos entre as instituições públicas, privadas e especiais, conforme tipologia apresentada pelo citado instituto de pesquisas, constantes na Tabela 1.

Estes números, aferidos apenas pela autodeclaração, representam um percentual de cerca de $2,7 \%$ da população indígena nacional, que conta, segundo dados do censo demográfico de 2010 , realizado pelo 
Instituto Brasileiro de Geografia e Estatística (IBGE), com um número de 817.963 pessoas que se reconhecem como indígenas no Brasil. Estes estão divididos em 305 etnias, falantes de 274 línguas diferentes, habitando em sua maioria a zona rural (61,5\%). Tal situação evidencia a premência das demandas por escolarização nas próprias comunidades, justificando a reivindicação crescente dos povos indígenas por maior atendimento educacional consoante com suas especificidades.

Tabela 1 - Matrículas de indígenas em IES no Brasil.

\begin{tabular}{cc} 
Tipos de IES & $\mathbf{N}^{\mathbf{0}}$ de Matrículas \\
\hline Públicas & 8.043 \\
Privadas & 13.801 \\
Especiais & 186 \\
Total & 22.030 \\
\hline
\end{tabular}

Fonte: INEP (2014).

Os dados da Tabela 1 demonstram que os estudantes indígenas, em sua maioria (62,6\%), estão cursando a graduação em IES privadas. Apenas pouco mais de $36 \%$ estudam em instituições públicas, a exemplo do que ocorre com as matrículas dos não indígenas, demonstrando que o Brasil segue a tendência de privatização da educação superior vigente em diferentes países.

No que se refere à distribuição geográfica das matrículas indígenas, há discrepância entre os locais de maior população indígena e os que abrigam mais estudantes que autodeclararam pertencimento étnico. A maioria destes estudantes está nas instituições situadas na Região Sudeste do Brasil, seguidos por aqueles que estudam no Norte e Nordeste, conforme dados da Tabela 2.

Tabela 2 - Matrículas de indígenas em IES no Brasil por região.

\begin{tabular}{cc} 
Regiões & $\mathbf{N}^{\mathbf{o}}$ de Matrículas \\
\hline Centro-Oeste & 2.612 \\
Nordeste & 4.768 \\
Norte & 4.886 \\
Sudeste & 8.141 \\
Sul & 1.623 \\
\hline
\end{tabular}

Fonte: INEP (2014). 
O fato de cerca de quase $37 \%$ dos estudantes estarem na Região Sudeste evidencia o processo de concentração de IES na região economicamente mais desenvolvida do país, corroborando mais uma vez a tese de que esta etapa da educação tem se constituído como um "sistema de elite". Apesar disso, no Norte e Nordeste, estão aproximadamente $43 \%$ dos estudantes indígenas cursando a graduação, com percentuais de $22,18 \%$ e $21,64 \%$ respectivamente.

No que se refere às modalidades de ensino, 19.444 (ou $88,26 \%$ do total de estudantes) estão em graduações presenciais e 2.586 (o que equivale a $11,74 \%$ ) fazem cursos à distância.

O conjunto destes dados pode servir para traçar um quadro geral da presença indígena nos cursos de graduação atualmente no Brasil. No entanto, para isso precisariam ser cruzados com outras fontes que qualifiquem melhor esta presença, dada a escassez de informações sobre as origens, os grupos de pertencimento, as línguas faladas por esses estudantes, bem como as políticas de acesso e de permanência que os contemplam. Elementos para compor este quadro poderiam ser buscados nas experiências acumuladas em mais de dez anos de ações afirmativas para indígenas no país, inicialmente surgidas através de iniciativas de algumas universidades e ampliadas com as políticas de expansão da educação superior, adotadas pelo governo federal a partir de 2003.

Uma maior presença de indígenas na educação superior resulta, em grande medida, dos esforços das lideranças, dos professores, dos estudantes e das organizações indígenas em geral, articuladas com as IES, sobretudo por meio de professores, que abriram "frentes de trabalho" dentro e fora de suas instituições para promoverem a formação superior de indígenas. Também a Fundação Nacional do Índio (Funai), através de apoio financeiro dispensado às IES e aos estudantes, e o MEC, que tem fomentado e apoiado ações junto às IES e aos estudantes no que se refere ao acesso e permanência destes, vêm contribuindo para essa mudança.

Como fruto destas formas de colaboração interinstitucional e intercultural surgiram ações que promoveram o acesso diferenciado (por meio de vestibulares específicos, reservas de vagas, cotas); a busca pela garantia da permanência ("bolsa" da Funai, Programa Bolsa Permanência 
do MEC); a criação de participação indígena nas IES (colegiados, conselhos, observatórios); a criação de unidades específicas no âmbito das IES (faculdades, institutos, núcleos) e as iniciativas de criação de novas instituições.

É a este último assunto que a parte seguinte do texto é dedicada, apresentando as propostas de criação de três novas iniciativas que pretendem se constituir em instituições voltadas para o atendimento das demandas específicas dos povos indígenas por educação superior.

2. Educação superior e povos indígenas: três iniciativas de colaboração intercultural e interinstitucional

A presença indígena na educação superior, inicialmente voltada para o atendimento de suas demandas por formação de professores para atuarem nas escolas de suas comunidades, remonta ao início dos anos 2000. Com o progressivo aumento da escolarização entre os povos indígenas ocorrido nas últimas décadas, as demandas por formação universitária foram ampliadas para diferentes áreas profissionais, colocando em evidência as dificuldades das IES em lidar com as especificidades dos povos indígenas. Na esteira deste movimento, surgiram as três iniciativas descritas a seguir, dedicadas ao atendimento de tais especificidades, constituindo-se em exemplos potenciais de colaboração intercultural e interinstitucional no campo da educação superior de indígenas.

\subsection{Instituto dos Conhecimentos Indígenas e Pesquisa do Rio Negro (ICIPRN)}

A proposta de criação do ICIPRN, no noroeste amazônico, resultou das discussões sobre a ampliação, para a educação superior, das experiências de educação escolar diferenciada vivenciadas pelos povos indígenas que habitam a região. Promovidas pela Federação das Organizações Indígenas do Rio Negro (FOIRN) ${ }^{4}$ em parceria com o

\footnotetext{
${ }^{4}$ A FOIRN foi fundada em 1987 pelos povos indígenas do Rio Negro com o objetivo de fortalecer a luta
} 
Instituto Socioambiental (ISA) ${ }^{5}$, estas discussões estão associadas ao movimento local de construção de projetos alternativos de educação indígena, que remonta ao final dos anos 1980.

Estes projetos alternativos vêm se constituindo por meio das escolas-piloto, criadas no âmbito do Projeto de Educação Escolar Indígena do Rio Negro, realizado pelo ISA e pela FOIRN no final da década de 1990. Por meio desta parceria se pretendeu criar "um novo sistema de escolas" (OLIVEIRA, 2011, p. 226), caracterizadas pela autonomia da gestão e pelo aprendizado via pesquisa. Estas diretrizes são dadas pelo Programa Rio Negro, que alberga a proposta de criação do ICIPRN.

Com o propósito de fortalecer os conhecimentos tradicionais na promoção do desenvolvimento sustentável ou do bem-viver dos diferentes povos rio-negrinos, o ICIPRN pode ser visto como um exemplo do que Daniel Mato (2008, p. 113) chama de colaboração intercultural, uma vez que a sua construção estaria baseada na ideia de produção de conhecimentos por meio de "diálogos y relaciones interculturales de valoración y colaboración mutuas [...] que partan de reconocer que hay diversidad de contextos y de prácticas intelectuales y de saberes".

Neste sentido, é possível compreendê-lo também como exemplo de colaboração interinstitucional, uma vez que, além do ISA e da FOIRN, pretende envolver diversas IES, institutos de pesquisa e outros órgãos nacionais e internacionais na promoção de programas integrados de ensino, pesquisa e extensão.

No entanto, como se verá adiante, o processo de construção da proposta para a criação do ICIPRN não foi isento de conflitos, colocando em perspectiva diferentes compreensões da política de produção dos conhecimentos dos e para os povos indígenas, em função, sobretudo, dos lugares institucionais e das formas de atuação dos seus parceiros.

No que se refere às articulações mais imediatas em prol da criação

pela demarcação das suas terras, promovendo ações, principalmente, nos campos da saúde, educação e desenvolvimento sustentável. Sediada na cidade de São Gabriel da Cachoeira (AM), é composta por mais de quarenta organizações indígenas distribuídas ao longo dos principais afluentes do Rio Negro.

${ }^{5}$ O ISA foi fundado em 1994 com sede em São Paulo e escritórios em diferentes estados. Atua entre os povos indígenas do Rio Negro desde a segunda metade da década de 1990. Para mais informações, consultar o endereço eletrônico www.socioambiental.org. 
do Instituto, o ISA e a FOIRN promoveram, durante cerca de cinco anos, uma série de eventos com o objetivo de discutir os seus aspectos conceituais e organizacionais junto aos diferentes atores sociais envolvidos, resultando na construção do seu projeto políticopedagógico (PPP) e do seu Programa de Formação Avançada Indígena (PFAI).

O primeiro destes eventos, denominado "Seminário da Arrancada", ocorreu em agosto de 2009; o segundo foi realizado em abril de 2010, discutindo o "Manejo do Mundo" pelos conhecimentos e práticas dos povos indígenas do Rio Negro; o terceiro ocorreu em novembro de 2010 e foi dedicado a apresentar e a debater as "Narrativas de Origem e as Rotas de Transformação", isto é, o lugar dos conhecimentos e conhecedores tradicionais para se pensar o futuro dos povos e comunidades desta região amazônica; o quarto encontro, em abril de 2014, resultou no desenho institucional do ICIPRN, caracterizado como um "instituto de produção de conhecimento intercultural, interdisciplinar e colaborativo" (CGE, 2014).

A estes se somaram outros encontros, como $01^{\circ}$ Workshop Internacional dos Povos Indígenas do Rio Negro e o $1^{\circ}$ Simpósio Diálogos Interculturais na Fronteira Pan-Amazônica, realizados, respectivamente, em dezembro de 2010 e em setembro de $2011^{6}$.

Nestes dois últimos encontros as discussões se desdobraram na proposta de criação de uma universidade indígena, havendo divergências de opiniões sobre o papel dos atores sociais indigenistas, notadamente o ISA. Afinal, em uma instituição deste tipo deveria ser conferida maior autonomia aos indígenas na gestão dos processos de produção dos seus conhecimentos, rompendo com seculares práticas de tutela denunciadas como ainda contemporaneamente correntes na região. Talvez por isso na caracterização do projeto o termo

\footnotetext{
${ }^{6}$ O Simpósio ocorreu com a participação das IES locais, da prefeitura e da Diocese de São Gabriel da Cachoeira, recebendo apoio da Organização das Nações Unidas para a Educação, a Ciência e a Cultura (Unesco) por meio do projeto Diversidad Cultural e Interculturalidad en Educación Superior en América Latina do Instituto Internacional para la Educación Superior en América Latina y el Caribe (IESALC). O evento foi selecionado dentre 210 propostas de 17 países latino-americanos enviadas para um edital de apoio a programas e projetos de investigação e/ou de promoção do bem-viver de instituições de ensino superior indígenas ou convencionais que contam com a participação e com os conhecimentos indígenas e afrodescendentes. Mais informações no endereço http://www.iesalc.unesco.org.ve/index.php?option=com_content\&view=article\&id=22\&Itemid=405\&lan $\mathrm{g}=\mathrm{es}$.
} 
"governança indígena" seja acionado por seus articuladores como maneira de contemplar as reivindicações da autodeterminação indígena em seus processos de escolarização em nível superior.

Não obstante a divergência de opiniões quanto ao modo de concretização da instituição de educação superior para os povos indígenas, seja o modelo "alternativo do ISA", seja o da "universidade indígena", apoiado por outros parceiros, o processo de construção da proposta seguiu adiante envolvendo diferentes atores sociais, prevalecendo a ideia de criação do Instituto.

$\mathrm{Na}$ busca pela consolidação de sua proposta, a FOIRN e o ISA mobilizaram diversos agentes e agências, entre eles o MEC, que, a partir de 2013, passou a aportar recursos técnicos e financeiros com vistas à realização de estudos sobre a viabilidade do projeto. Assim, em novembro daquele ano, o MEC contrata o Centro de Gestão e Estudos Estratégicos (CGEE) para elaborar o modelo institucional jurídico do ICIPRN. Como resultado, foi publicado em 2014 o documento intitulado Apoio à criação de uma instituição de ensino superior indígena.

De acordo com esta publicação, o ICIPRN será instituído como uma organização social (OS), forma jurídico-institucional encontrada pelos articuladores da proposta para atender ao modelo de governança negociado com os povos indígenas. Tal escolha foi justificada pela necessidade de maior flexibilidade nos processos de gestão, a ser constituído por instâncias colegiadas nas quais está prevista a participação dos indígenas.

Em seu organograma, são propostas instâncias de natureza executiva, como diretorias e coordenações, e outras deliberativas, como os conselhos de administração, de ensino, de pesquisa e extensão e fiscal, acrescidos de um Conselho Deliberativo Indígena. Este último foi concebido com o objetivo de legitimar a proposta a partir da ideia de uma maior representatividade dos diferentes povos indígenas rionegrinos nos processos de gestão do ICPRN.

Para a efetivação do Programa de Formação Avançada Indígena do ICPRN, é proposta a formação de uma rede de colaboradores constituída por profissionais ligados a instituições de educação e de pesquisa nacionais e internacionais, além de especialistas e formadores indígenas. 
Assim, o Instituto estaria baseado em parcerias interinstitucionais e formas de colaboração intercultural realizadas por meio de convênios e acordos de cooperação entre os diferentes agentes e agências envolvidos com a educação escolar indígena e a educação superior. Seu princípio norteador, como já indicado, seria a ideia de promoção do bem-viver para os povos indígenas da região no diálogo entre conhecimentos tradicionais e conhecimentos da ciência acadêmica.

Tal objetivo manifesto passa, no entanto, pela mediação do principal parceiro da FOIRN neste e em outros projetos, o ISA, defensor de um modelo intercultural alternativo às formas "ocidentalizadas" de escolarização e de produção do conhecimento acadêmico. É importante destacar que este modelo está ligado a questionamentos sobre as políticas de propriedade intelectual no que se refere aos usos, sobretudo comerciais, dos produtos resultantes da aplicação dos conhecimentos das populações tradicionais e povos indígenas.

Para a realização das atividades de formação e pesquisa é prevista a criação de cinco núcleos regionais localizados nas escolas indígenas de ensino médio apoiadas pelo ISA na região dos rios Uaupés, Tiquié e Baixo Uaupés, Alto Rio Negro, Médio Rio Negro e Içana. Com esta iniciativa, as escolas seriam diretamente beneficiadas com a instalação dos equipamentos de infraestrutura do Instituto, que passariam a servir também aos seus estudantes, além de potencializar as ações dos pesquisadores indígenas já existentes. Assim, poder-se-ia fortalecer o papel dos conhecimentos indígenas na gestão dos seus territórios e no desenvolvimento sustentável da região.

Sob tal perspectiva, o ICIPRN é apresentado com um espaço de exercício da autodeterminação indígena na produção dos seus conhecimentos e processos linguísticos, uma vez que suas práticas de ensino e pesquisa levarão em conta as especificidades culturais, sociais, linguísticas, ambientais e econômicas dos povos e comunidades assistidos por suas atividades.

O ICPIRN ofertará cursos tecnológicos nas áreas de Gestão Ambiental e Agroecologia, contemplando também a área linguística, em função da diversidade de línguas faladas pelos povos da região, dando prioridade à tradução, à semântica e à cosmologia, podendo ser inserida "como Temas Transversais ou Estudos Complementares no currículo do 
Programa de Formação" (CGE, 2014).

Prevê-se a organização do currículo em dois ciclos (básico e específico), além de eixos temáticos a serem definidos de acordo com as demandas das comunidades. Nele é proposta também a utilização de um calendário acadêmico flexível, em consonância com a sazonalidade das manifestações culturais e atividades econômicas das diferentes comunidades indígenas.

A certificação dos estudantes será feita pelas IES parceiras que chancelarão o reconhecimento acadêmico dos diplomas expedidos pelo ICIPRN. Esta questão também não se constituiu, durante os debates para a construção da proposta, como um ponto pacífico entre as diferentes agências e agentes participantes.

Para alguns o processo de certificação funcionaria como uma espécie de "domesticação" ou de subordinação ao modelo não indígena de produção do conhecimento, uma vez que adequado às exigências protocolares do mundo acadêmico sem um maior questionamento a respeito das políticas universitárias de produção e consumo do saber científico. Tal crítica faz referência, sobretudo, às experiências de indígenas na educação superior ao enfrentarem os desafios postos pelos currículos monoculturais das universidades.

Para outros, a não certificação poderia representar uma espécie de dissociação entre ensino e pesquisa, em detrimento do primeiro, o que poderia provocar a minimização ou mesmo o descarte das instituições de educação superior. Por isso, nos debates sobre a criação do ICPRN, houve aqueles que defenderam a importância do reconhecimento da diplomação dos estudantes, tendo em vista o seu valor nos mercados educacional e do mundo do trabalho. Noutros termos, a formação de profissionais indígenas foi percebida, principalmente pelos indígenas, como ponto estratégico para a autonomia do movimento indígena e para o profissional indígena em seu reconhecimento no mundo do trabalho ou associações profissionais.

Não obstante a polêmica em torno dos certificados, emblemática das tensões entre defensores do modelo alternativo e apoiadores da ideia de certa apropriação indígena do "paradigma universitário", prevaleceu a ideia de adequação da instituição às demandas dos povos indígenas da região por formação superior, orientada pelos princípios 
da interculturalidade e da especificidade.

Em suma, na construção da proposta, tendo por base as experiências de educação escolar indígena diferenciada implantadas na região nas últimas décadas, foram postas em evidência as ideias de colaboração intercultural, de parcerias institucionais, governança indígena e indigenista, produção e gestão dos conhecimentos tradicionais dos diferentes povos indígenas do Rio Negro e as necessidades de suas formações profissionais em consonância com seus projetos de bem-viver.

\subsection{Câmpus Indígena da Universidade Federal da Fronteira Sul (UFFS)}

Esta iniciativa resultou das articulações empreendidas entre a UFFS e as lideranças indígenas que habitam a Região Sul do Brasil, predominantemente kaingang e considerada por eles como estratégica para o fortalecimento tanto da missão institucional da universidade, quanto dos processos educacionais e de desenvolvimento sustentável destas comunidades.

A criação do câmpus em terra indígena ( $\mathrm{TI}$ ) seria, então, um desdobramento de tais articulações junto aos agentes dos poderes públicos locais e agências nacionais, como o Ministério Público Federal (MPF), a Funai e a Secretaria Especial de Saúde Indígena (Sesai) do Ministério da Saúde (MS).

Com câmpus nos três estados brasileiros que compõem a mesorregião Grande Fronteira do Mercosul (norte e noroeste do Rio Grande do Sul, oeste do estado de Santa Catarina e sudoeste do Paraná), a UFFS está situada em uma região habitada, além dos Kaingang, pelos Xokleng e pelos Guarani-Mbyá. No entanto, são os primeiros os protagonistas, tendo em vista a expressividade política local e nacional de suas lideranças e o fato de se constituírem no povo indígena mais populoso do Sul do país, com terras indígenas espalhadas desde a Região Sudeste.

A UFFS, desde a sua instalação, em 2010, desenvolveu iniciativas ligadas às demandas dos movimentos sociais e adotou formas diferenciadas de ingresso aos seus cursos, mesmo antes da vigência da 
chamada Lei de Cotas7. No que se refere aos povos indígenas, é criado, em 2013, o Programa de Acesso e Permanência dos Povos Indígenas (PIN), que prevê até duas vagas suplementares por meio de processo seletivo diferenciado a fim de superar a inadequação da Lei de Cotas para as demandas indígenas.

Mas foi com a proposta de criação do câmpus indígena que essa universidade pretendeu construir seu mais importante capital simbólico junto aos povos indígenas do Sul do Brasil. Relacionado à imagem de instituição promotora da democratização do ensino superior para populações social, geográfica e economicamente marginalizadas, este capital vem sendo acionado pela UFFS como instrumento principal em suas negociações com o MEC para a construção do câmpus que pretende atender exclusivamente estudantes indígenas.

As lideranças indígenas ligadas aos processos de construção e de divulgação da proposta, por sua vez, têm buscado apoio em diferentes setores dos poderes públicos e agentes do campo indigenista. Conferências, assembleias e encontros que discutem as políticas públicas dirigidas aos povos indígenas também têm se convertido em espaços de divulgação e de busca de apoio.

Com o objetivo de buscar parcerias, a UFFS promoveu, no ano de 2012, dois eventos: o $1^{\circ}$ Congresso Sul-Brasileiro de Promoção dos Direitos Indígenas (Consudi) e o $1^{\circ}$ Encontro sobre Diversidade na UFFS. Tais eventos tiveram também o propósito de dar visibilidade às ações que a universidade vem desenvolvendo no sentido de democratizar o acesso e a permanência dos povos indígenas na educação superior, bem como com o intuito de estreitar canais de comunicação com as comunidades indígenas que habitam a mesorregião da Grande Fronteira do Mercosul.

Ao longo dos anos de 2014 e 2015, foram realizados vários eventos com vistas a consolidar o projeto de criação e implantação do câmpus indígena. Em 2014, uma versão do projeto, ainda sem a definição de qual comunidade indígena sediaria o câmpus, foi entregue ao MEC.

\footnotetext{
${ }^{7}$ Lei 12.711 de 29 de agosto de 2012, que dispõe sobre a reserva de vagas nas universidades federais e nos Institutos Federais de Educação Tecnológica (IFETs), regulamentada pelo Decreto 7.824 e pela Portaria Normativa 18 do MEC, ambos datados de 11 de outubro do mesmo ano.
} 
De acordo com o documento, esta iniciativa seria "uma ação afirmativa de resgate, promoção e valorização da cultura, das práticas produtivas e comerciais, das relações sociais, dos perfis institucionais e da defesa territorial dos povos indígenas, cuja fundamentação legal é ampla e variada" (BRASIL, 2015, p. 16).

Como uma das justificativas apontadas para a sua criação, o território indígena funcionaria como espaço de prática para os projetos pedagógicos dos cursos, propiciando o fortalecimento das escolas indígenas de educação básica. O câmpus também teria por propósito possibilitar a criação e o aperfeiçoamento de modelos de desenvolvimento sustentável para as comunidades e povos indígenas da região.

Está prevista, inicialmente, a criação de seis cursos de graduação (Agronomia, Ciências Biológicas, Enfermagem, Administração, Pedagogia, Licenciatura Indígena), apresentados com a finalidade de promover o desenvolvimento econômico, social e cultural das terras indígenas e suas instituições inseridas na área de abrangência da UFFS. Suas escolhas teriam sido, dessa forma, discutidas com os indígenas, visando atender suas demandas por formação superior, tidas como fundamentais para a promoção de suas autodeterminações e projetos de bem-viver.

Além dos cursos citados, o documento prevê a oferta de cursos de pós-graduação, aperfeiçoamento e extensão, somados à dimensão da pesquisa como vetor principal no desenvolvimento de todas as atividades acadêmicas.

Os primeiros cursos de graduação disponibilizariam 180 vagas por ano e seriam organizados em regime de alternância, caracterizado pelo estabelecimento de dois momentos principais no processo formativo: o tempo universidade (regime de internato) e o tempo comunidade (atividades pedagógicas e de pesquisa em campo).

A estrutura física do câmpus foi discutida com os indígenas, tendo como mote suas referências culturais de construção e de organização dos espaços e sustentabilidade de suas comunidades.

Não obstante ser apresentado como espaço de exercício do protagonismo e autodeterminação indígenas, o câmpus da UFFS não atende ao modelo de uma "instituição própria", dados os limites da 
participação ou controle social dos índios na gestão administrativa, pedagógica e financeira. Há que se considerar, ainda, as possíveis implicações da construção de um equipamento institucional da universidade em terra indígena, o que poderá colocar novos elementos na relação entre a comunidade e a universidade. As pesquisas realizadas, por exemplo, farão surgir um conjunto de questões importantes para se pensar sobre autoria, tradução, propriedade intelectual, formas de colaboração intercultural, ética científica e política, dentre outras categorias do pensamento político atual importantes no campo indigenista nacional e internacional.

Por fim, vale a pena chamar a atenção para o papel que a UFFS vem desempenhando no campo da promoção da educação superior para os povos indígenas da Região Sul. Esta IES tem procurado estender, para as populações indígenas em sua área de abrangência, as ações da política de expansão, descentralização e democratização da educação superior pública.

Neste sentido, a UFFS tem buscado atender as reivindicações dos povos indígenas locais por formação superior, dando mostras de como é possível promover uma maior democratização da educação superior.

\subsection{Instituição de educação superior intercultural indígena}

No ano de 2014 tomou corpo, no âmbito do MEC, os debates em torno da criação de uma instituição de educação superior intercultural indígena com a publicação da Portaria 52, no dia 24 de janeiro, instituindo um grupo de trabalho (GT) responsável pela realização de estudos necessários para tal fim. De acordo com a referida portaria, em seu artigo $1^{\circ}$, esta instituição deverá promover, por meio do ensino, da pesquisa e da extensão, "atividades voltadas para a valorização dos patrimônios epistemológicos, culturais e linguísticos dos povos indígenas, considerando-se suas demandas e necessidades" (BRASIL, 2015, Art. 1).

De início, vale destacar que a criação do GT é um desdobramento das ações do Programa Nacional dos Territórios Etnoeducacionais 
(PNTEE) ${ }^{8}$, lançado também pelo MEC no mesmo ano de 2014 como forma de atender demandas oriundas dos processos de implementação dos Territórios Etnoeducacionais (TEEs).

Fruto da articulação entre a Secretaria de Educação Superior (SESu) e a Secretaria de Educação Continuada, Alfabetização, Diversidade e Inclusão (Secadi), o GT foi composto por profissionais indígenas e não indígenas ligados à temática da educação superior para indígenas no país 9 .

Durante os trabalhos do GT, ficou acordado que o produto final seria um relatório a ser entregue às equipes gestoras do MEC e à Comissão Nacional de Educação Escolar Indígena (CNEEI) para os encaminhamentos que se fizessem necessários, a partir de suas respectivas competências. De modo geral, as discussões do GT giraram em torno de propostas ligadas tanto ao conteúdo quanto ao formato de uma instituição de educação superior de indígenas.

Foi consenso a definição do protagonismo indígena como eixo norteador da futura instituição, representado pelas formas de participação dos diferentes povos nos processos de gestão administrativa e acadêmica da instituição e na promoção dos seus conhecimentos, saberes e técnicas nas atividades de ensino, pesquisa e extensão.

No que se refere ao formato, foram elencadas possibilidades de criação de institutos de formação indígena nas universidades e institutos federais, o fortalecimento e organização das experiências já em desenvolvimento nas IES por meio da criação de uma rede de educação superior para os povos indígenas e, por fim, a criação de uma universidade indígena. Embora, em alguns momentos das discussões, um ou outro formato ganhasse relevância, prevaleceu a ideia de que esses formatos poderiam ser adotados de modo articulado com a finalidade de se criar uma instituição "própria" a longo prazo. A curto e

\footnotetext{
${ }^{8}$ Conjunto articulado de ações de apoio técnico e financeiro do MEC aos sistemas de ensino para a organização e o fortalecimento da educação escolar indígena, conforme disposto no Decreto 6.861, de 27 de maio de 2009. Este decreto instituiu os Territórios Etnoeducacionais, definidos como espaços institucionais em que a União, os estados e os municípios, as comunidades indígenas, as organizações indígenas e indigenistas e as instituições de ensino superior pactuam ações de promoção e de adequação da educação escolar indígena às realidades sociais, históricas, culturais, ambientais e linguísticas dos grupos e comunidades indígenas.

${ }^{9}$ Nem todos os membros nomeados na portaria de criação do GT puderam compô-lo ou ter uma presença efetiva nas reuniões por razões diversas.
} 
médio prazo, a estratégia acordada foi criar um programa de fortalecimento da educação superior de indígenas por meio de ações estratégicas do MEC em diversas frentes.

O conjunto destas questões é referenciado nas descrições que seguem dos encontros de trabalho do GT realizados ao longo do ano de 2014.

A primeira reunião do GT ocorreu em março e objetivou, além da sua instalação e definição do cronograma de encontros, discutir as ideias preliminares de cada um de seus membros sobre a criação de uma instituição de educação superior de indígena.

No segundo encontro, ocorrido em abril daquele ano, o objetivo foi discutir documentos arrolados na reunião anterior como subsídios para a formulação de uma proposta que orbitava, naquele momento, em torno de duas estratégias principais: a formação de uma rede organizando as experiências de formação já realizadas nas universidades e a criação de uma instituição própria.

Por conseguinte, o GT buscou conhecer experiências de instituições que possuíssem modelos pedagógicos e organizacionais alternativos aos convencionais das universidades brasileiras, tais como a UFFS, com o projeto do câmpus indígena; a Faculdade Zumbi dos Palmares e a proposta de inclusão de estudantes negros na educação superior; a Escola Nacional Florestan Fernandes (ENFF), dirigida pelo Movimento dos Trabalhadores Rurais Sem Terra (MST), que promove a formação profissional e política dos militantes e simpatizantes do MST; o Programa Rede de Saberes: permanência de indígenas na educação superior, desenvolvido pela UFMS, pela Universidade Católica Dom Bosco (UCDB) e pela Universidade Estadual de Mato Grosso do Sul (UEMS); a Faculdade Latino-Americana de Ciências Sociais (Flacso), que forma uma rede de cooperação no campo da educação superior na América Latina e no Caribe; e a proposta de criação da Universidade das Artes, que se destinaria a fomentar programas de formação artística e de produção cultural ${ }^{10}$. Cada uma destas experiências aportou ideias para o possível desenho da instituição de educação superior intercultural indígena.

\footnotetext{
${ }^{10}$ Embora a proposta de criação desta universidade não tenha se consolidado, a parceria MEC/MinC criou o Programa Mais Cultura nas Universidades, cujo primeiro edital foi lançado em outubro de 2014.
} 
No dia 26 de maio, ocorreu o quarto encontro do GT, no qual ficou acordada como característica da futura instituição indígena a mobilidade de seus docentes e discentes entre os diferentes institutos ou câmpus que seriam criados nas universidades parceiras, optando-se, assim, pelo modelo de uma universidade indígena multicâmpus. Foram propostos, ainda, a criação de uma fundação para gerir os recursos da universidade e a entrega do documento final do GT no final de 2014

A quinta reunião do GT aconteceu em julho, quando foram discutidas questões relacionadas à governança dos povos indígenas, ao seu protagonismo nos espaços de gestão acadêmica, administrativa e financeira, chamando a atenção, sobretudo, para a importância da presença e participação dos sábios e lideranças indígenas.

A partir deste encontro, o GT decidiu formatar o seu documento final em duas grandes estratégias: a primeira seria o fortalecimento, pelo MEC, das experiências de educação superior de indígenas já existentes e a segunda seria a criação de uma instituição de educação superior indígena, chamada de Universidade Intercultural Indígena (UII).

Para o GT, a UIl funcionaria em rede a partir da criação de institutos de formação indígena nas IES que já possuíssem trabalhos desenvolvidos na educação superior de indígenas. Além disso, tais institutos seriam coordenados a partir de uma sede localizada em Brasília. Para a constituição desta universidade em rede, deveriam ser destinados fundos específicos, com gestão indígena e composição majoritária do quadro docente e técnico por indígenas.

Essa proposição encontra, no cenário brasileiro atual, grandes entraves, tais como a resistência à criação de universidades temáticas, como seria a indígena, por parte dos gestores das políticas de educação superior, além da sua criação passar por um projeto de lei a ser aprovado no Congresso Nacional, formado, neste momento, em sua maioria, por parlamentares pouco favoráveis às demandas dos povos indígenas.

Diante deste contexto, o MEC optou por implementar, com base na primeira estratégia apresentada pelos membros do GT, a Rede Brasileira de Educação Superior Intercultural Indígena, oferecendo apoio financeiro e recursos humanos para as IES participantes.

Vale informar que, a despeito das mudanças, alguns aspectos da 
proposta original do GT permanecem na nova configuração anunciada pela presidenta da República, Dilma Rousseff, durante a abertura da etapa nacional da $1^{\text {a }}$ Conferência Nacional Política Indigenista, ocorrida em Brasília entre os dias 17 a 20 de novembro de 2015.

Não custa lembrar também que a ideia da rede universitária de educação superior para os povos indígenas, com a criação de institutos nas universidades, era proposta já defendida por membros do GT como etapa inicial para se consolidar o projeto de uma universidade indígena. No relatório prevaleceu, no entanto, o posicionamento dos indígenas integrantes do grupo, que foram favoráveis à criação da universidade, ainda que esta fosse constituída "em rede" e a longo prazo.

Para tanto, os indígenas membros do GT decidiram fazer mobilizações junto a diferentes atores sociais, dentre eles o próprio movimento indígena, políticos aliados da causa indígena, instituições de governo e organismos internacionais, com vistas a angariar apoio político "externo" para a criação da UlI. Dessa maneira, advogam que a simples inclusão dos indígenas nas universidades "convencionais" não tem promovido a autonomia reivindicada, vista como possível de se conquistar em "instituições" próprias.

\section{Conclusão}

Se as IES brasileiras, por um lado, têm buscado criar espaços específicos, visando um melhor atendimento das demandas dos povos indígenas - seja através da adoção de ações e políticas de acolhimento para os estudantes, seja criando espaços de participação em suas instâncias de deliberação -; por outro lado, elas pouco têm conseguido avançar no que diz respeito à interculturalização dos conhecimentos, possível efeito de uma maior presença indígena nas universidades.

Este pode ser visto como um dos motivos principais para a proposição de criação de instituições que se pretendem promotoras de um maior protagonismo indígena, como o câmpus indígena da UFFS e a Rede Brasileira de Educação Superior Intercultural Indígena, a ser organizada pelo MEC, ou de instituições próprias, a exemplo do ICIPRN e da universidade indígena defendida no âmbito do GT criado pelo MEC. 
Sendo assim, o movimento indígena, ao participar das negociações de tais propostas - tanto no que se refere ao lugar de seus modos de vida e epistemologias na produção do conhecimento quanto à gestão administrativa e docente -, busca construir, por meio destas novas instituições, suas formas de governança na educação superior.

Os exemplos descritos sugerem que a democratização da educação superior passa também pela interculturalização das IES ao incorporarem as especificidades da pluralidade étnica e sociocultural brasileira. Nesta direção, compreende-se que a interculturalidade com equidade para todos deve ser um dos princípios de toda a política de educação superior, uma vez que ela não interessa apenas aos grupos socioculturalmente diferenciados, mas, como afirma Mato, ela é

$$
\begin{aligned}
& \text { condición necesaria para mejorar la calidad de la } \\
& \text { Educación Superior de los diferentes países, y sus } \\
& \text { posibilidades de aprovechar mejor las potencialidades } \\
& \text { de la diversidad de sus poblaciones nacionales y de } \\
& \text { construir sociedades más equitativas, que sean social y } \\
& \text { ambientalmente sostenibles (MATO, 2012, p. 19). }
\end{aligned}
$$

Vale salientar que interculturalizar a educação superior não significa apenas estabelecer um diálogo mais horizontalizado entre diferentes saberes, mas também questionar os lugares dos povos indígenas nas universidades, propondo formas de colaboração intercultural nas quais estes ocupem lugares estratégicos no ensino, na pesquisa e na gestão das IES. Dessa maneira, os indígenas reivindicam o exercício do protagonismo, da autodeterminação e da governança no que pode vir a se configurar como instituições de educação superior próprias.

Assim, a educação superior de indígenas no Brasil, a exemplo do que vem ocorrendo há alguns anos em outros países da América Latina, coloca em perspectiva a proposta de universidades comprometidas com as questões sociais, econômicas, ambientais, culturais e linguísticas das comunidades e povos indígenas, necessárias à promoção do seu bemviver e de toda a sociedade envolvente.

Neste sentido, tem-se discutido como a criação e o fortalecimento de universidades indígenas no contexto latino-americano têm favorecido a democratização do acesso e permanência dos indígenas na 
educação superior (MUÑOZ, 2007).

Da mesma forma, entende-se, no caso brasileiro, que a criação de instituições próprias busca responder melhor às demandas dos povos indígenas pelo acesso e permanência na educação superior com a qualidade e a pertinência sociocultural e linguística requeridas.

\section{Referências bibliográficas}

MATO, Daniel. No hay saber "universal": la colaboración intercultural es imprescindible. Alteridades, Iztapalapa, v. 18, n. 35, p. 101-116, 2008.

Las iniciativas de los movimentos indígenas em educación superior: un aporte para la profundización de la democracia. Nueva Sociedad, Santiago, n. 227, p. 102-119, 2010.

(Org.). Educación Superior y Pueblos Indígenas y Afrodescendientes em America Latina: normas, políticas y prácticas. Caracas: Iesalc/ Unesco, 2012.

MUÑOZ, Manuel Ramiro. Educación superior y pueblos indígenas en América Latina y el Caribe. In: INFORME SOBRE LA educación superior en américa latina y el caribe 2000-2005. La metamorfosis de la educación superior. 2007, p. 129-143. Disponível em: www.iesalc.unesco.org.ve/index.php?option... Acesso em: 30 dez. 2016.

NASCIMENTO, Rita Gomes. Entre "inclusão social e étnico-racial” e a busca por "autonomia e protoganismo indígena": mapeamento de ações para a educação superior de povos indígenas no Brasil. In: MATO, Danie et.al. (Org.). Educación superior y pueblos indígenas en América latina: contextos y experiencias. Sáenz Peña: Universidad Nacional de Tres de Febrero, 2015. p. 97-116.

OLIVEIRA, Lúcia Alberta Andrade de. Alto Rio Negro: gestão compartilhada de educação escolar indígena. In: RICARDO, Beto; RICARDO, Fany (Org.). Povos Indígenas no Brasil 2006/2010. São Paulo: Instituto Socioambiental, 2011. p.225-229.

SOUZA LIMA, Antônio Carlos de. Educação Superior para Indígenas no Brasil: sobre cotas e algo mais. 2007. Seminário Formação Jurídica e Povos Indígenas: Desafios para uma educação superior, 21, 22 e 23.03.2007. Disponível em: www.ufpa.br/juridico/documentos/textoAntonio.pdf . Acesso em: 30 dez. 2016.

TROW, M. Reflections on the Transition from Elite to Mass to Universal Access: Forms and Phases of Higher Education in Modern Societies since WWWII, 2005. Disponível em: http://escholarship.org/uc/item/96p3s213\#page-1 . Acesso em: $30 \mathrm{dez}$. 2016. 


\section{Documentos}

BRASIL. Lei 9.394/96. Estabelece as diretrizes e bases da educação nacional (LDB). Brasília, 1996. Disponível em: http://www.planalto.gov.br/ccivil_03/_ato20112014/2014/lei/113005.htm. Acesso em: 30 dez. 2016.

Lei 10.172/2001 - Aprova o Plano Nacional de Educação e dá outras providências. Brasília, 2001. Disponível em: http://www.planalto.gov.br/ccivil_03/leis/leis_2001/110172.htm. Acesso em: $30 \mathrm{dez}$. 2016.

Projeto de criação do câmpus indígena da Universidade Federal da Fronteira Sul (UFFS), 2014a.

Portaria no 52, de 24 de janeiro de 2014. Brasília: Ministério da Educação, 2014b. Disponível em: http://pesquisa.in.gov.br/imprensa/jsp/visualiza/index.jsp?jornal=2\&pagina $=10 \& d a t a=2$ 7/01/2014. Acesso em: 30 dez. 2016.

Lei 13.005/2014. Aprova o Plano Nacional de Educação e dá outras providências. Brasília, 2014c. Disponível em: http://www.planalto.gov.br/ccivil_03/_ato2011-2014/2014/lei/113005.htm. Acesso em: 30 dez. 2016.

Documento de Trabalho do GT universidade indígena. 2015.

CGE - CENTRO DE GESTÃO de Estudos Estratégicos (CGE). Apoio à criação de uma instituição de ensino superior indígena. Brasília: CGE, 2014.

INEP. Censo da educação superior. 2014. Disponível em: http://portal.inep.gov.br/ . Acesso em: 30 dez. 2016.

MEMÓRIAS das Reuniões do Grupo de Trabalho (GT) instituído pela Portaria MEC n' 52/2014, CGEEI/MEC, 2014/2015. 